\author{
Military Technical College \\ Kobry El-Kobbah, \\ Cairo, Egypt.
}

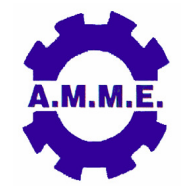

\title{
LAUNCHING RECOIL DUMPING IMPROVEMENT FOR MLRS BY USING A RING WIRE ROPE ABSORBER
}

\author{
A. Kari, D. Jerkovic ${ }^{*}$, M. Milinovic ${ }^{\star *}$ and S. Ilic ${ }^{* *}$
}

\begin{abstract}
Paper considers model of shock loads dumping during launching by using the wire rope absorber. Loadings are generated and initiated by shock forces, appeared as reaction of nozzle gases at muzzle velocities conditions on the Multiple Launch Rocket System (MLRS). Dumping of impulse loadings could be realized by design of wire rope absorber tested and represented in this paper. Absorber is typical nonlinear, no periodical dumper. Experimental model of absorber is tested by equipment able to simulate approximations of real launching forces. Different short time dynamical loadings are approximated with linear and harmonic functions as initial shock and unsteady forces. Relations between initiation shock forces and response forces at the exit of wire rope absorber are compared experimentally by results tested in real time. Results presented in the paper shows force-time performances and possibilities for application of new ring designed of wire rope absorber used at MLRS combat platforms.
\end{abstract}

\section{KEY WORDS}

MLRS, dumping, shock loading, wire rope absorber.

* Teaching Assistant, Military academy, University of Defense, Belgrade, Serbia.

** Professor, Faculty of mechanical eng., University of Belgrade, Belgrade, Serbia.

${ }^{* * *}$ Assistant professor, Military academy, University of Defense, Belgrade, Serbia. 


\section{NOMENCLATURE}

$A_{g g} \quad$ Area of gas-generator front.

$A_{m c} \quad$ Cross-section areas of barrel nozzle.

$A_{\text {mgg } 1,2} \quad$ Cross-section areas of gas-generator nozzles.

$F_{g g 1,2} \quad$ Forces of gas-generator.

$F_{i n p}^{\max } \quad$ Maximal experimental input shock force.

$F_{\text {out }}^{\max } \quad$ Maximal measured output dumped force.

$F_{p c} \quad$ Force of pressure in barrel.

$F_{\text {rtotal }} \quad$ Total recoil force at gas-generator launching.

$F_{\text {rec } 1,2,3}$ Components of $F_{\text {rtotal }}$.

$F_{u g} \quad$ Total impact force of gases.

$F_{1} \quad$ Force as a result of the total gas pressure behind the shock wave.

$F_{2} \quad$ Shock wave force that is appeared as the rejection of the front plate of launcher.

$M_{a} \quad$ Mach number.

$P_{a} \quad$ Force of ambient pressure.

$P_{02} \quad$ Total pressure behind the shock wave.

$S_{a} \quad$ Area of launcher front plate.

$U_{e c} \quad$ Velocity of gas flow through the nozzle of barrel.

$U_{\text {egg 1,2 }} \quad$ Velocities of gas flow through the nozzle of gas-generator.

$V_{1} \quad$ Velocity in front of the shock wave.

$V^{*} \quad$ Velocity of rejected (reflected) flow, behind the shock wave.

$\dot{m} \quad$ Mass flow.

$\dot{m}_{c} \quad$ Mass flow through the nozzle of barrel.

$\dot{m}_{g g 1,2} \quad$ Mass flow through the nozzle of gas-generator.

$p_{a} \quad$ Ambient pressure.

$p_{c} \quad$ Pressure in barrel.

$p_{g g} \quad$ Pressure in gas-generator.

$r_{1} \quad$ Equivalent radius of launch box front plate.

$x \quad$ Path of rocket.

$y_{\max } \quad$ Maximal measured displacement of absorber plate.

$\kappa \quad$ Coefficient of polytrophic curve.

$\rho_{1} \quad$ Ambient density in front of the shock wave.

\section{INTRODUCTION}

In the most general terms, during the combat use of MLRS is exposed to static and dynamic forces [1, 2]. Static forces acting on the MLRS are:

- Weight of launcher own construction, and 
- Total weight of the rockets which changes during launch, but does not change during transport.

The problems of static loads are resolved during the design by reasonable ratio of requirements for mass and construction robustness, because of special requirements arising from combat use. In general, dynamic loads are the main problem of weapon design due to the impulse character of the forces and moments that occur most frequently in the exploitation of weapons and ammunition in combat conditions. At the MLRS, loads can be grouped as follows [3]:

1. loads caused by mechanical forces contact which include, for example, rockets locking forces in the launcher,

2. gas-dynamic loads, which include:

a. gas-dynamic loading of launcher box front plate under the action of powder gases from the rocket engine,

b. internal-ballistic load when using gas-generator for increasing rocket initial velocity,

c. loading from the effects of explosion shock wave impulse excitation

3. loads caused by a gust of wind - especially important in systems with vertical launching

4. transport loads

Gas-dynamic loads are the result of complex processes which are deterministic, but, sometimes, in combat conditions, and stochastic and the evaluation of its effects, by the resulting direction and intensity, is more difficult to assess. For them, there are the specific standards that simulate and regulate them. In addition, these loads represent the very essence of military technology and the underlying cause of military and civilian construction diversity.

For this reason, in this paper special attention primarily was dedicated gas-dynamic loads of MLRS and their absorption. Hence, the essence of dynamic loads in military technology is a phenomenon of impulse caused by the shock wave of external loads and high pressure of internal loads during firing. Such loading causes specific timevariable force profile, difficult to describe, but predictable. Their studying always reveals new examples that have not been considered as experimental and theoretical yet. One of such research attempt is this paper.

The main aim and tasks of this study was to determine [3]:

- Is there a correlation between gas-dynamic loads as dynamic excitation of launcher structures that can be adopted as a universal load profile that appears on the launcher?

- Can it be such a form of time-variable forces successfully simulated experimentally for the evaluation of its absorption and damping by a new type of ring wire rope absorber?

If this approach can be universally set for use in the launch devices, further research could show that its extension to other types of conventional weapons and military equipment with similar loadings is possible.

There are two principal approaches for solving performances of typical dynamical loads. First approach is mathematical modeling of displacement and theoretical 
comparison of their absolute and relative coefficient and performances. Second approach is modeling of the forces and their theoretical absolute and relative performances and coefficients. Both approaches needs experimental work and have to be supported by experimental data of real behavior for modeling and designed performances. Considering parts and elements in real structure usually are tested and evaluated on dynamical loads.

Types of these loads depend of construction, assemblies and subassemblies and also of goals in functional performances. This work shows distribution of shock pressure on the contact surfaces attacked by forces from different space directions initiated by launching of rocket. Computer simulation shows good possibilities for modeling, but some input data needs to be more precise and taken from real experiments.

The basic concept of this paper was to set up methodology for approximate testing and estimation of possible use of ring wire rope absorber in the cases of combat loadings on MLRS.

\section{SHOCK FORCES ON MLRS, APPEARED AS REACTION OF NOZZLE GASES}

As already mentioned the basic discussed gas-dynamic forces are:

- Fire shock loadings, initiated by rockets exhaust jet over pressure, attack on front launcher plate at MLRS, during launching and

- Shock loadings initiated by interior ballistics during active or semi active (active to reactive) launching of the rocket ammunition.

When leaving the rocket after moving through the barrel, the combustion gases from the rocket engines perform chemical, physical and mechanical (impact) affect on the front panel MLRS, and therefore the whole launcher. To study the oscillatory movement of the launcher, as well as the mechanical load of the launcher, the most influential is a mechanical impulse, caused by the effects of combustion products of rocket fuel to the front plate of the rocket launcher in a short period of time, Fig. 1 [1, 2].

Effect of force initiated by gas products of rocket nozzle, conditionally can be divided in to the two constitutions:

$F_{1}$ - The force as a result of the total gas pressure behind the shock wave and

$F_{2}$ - Shock wave force that is appeared as the rejection of the front plate of launcher.

Thus, the total impact force of gases is:

where:

$$
F_{u g}=F_{1}+F_{2}
$$

$$
F_{1}=2 \pi \int_{0}^{r_{1}} P_{02} r d r \quad \text { and } \quad F_{2}=2 \pi V^{*} \int_{0}^{r_{r}} n d k d r .
$$

Based on gas-dynamic analysis, and a detailed presentation given in, [1], and the impact force of gases is obtained in the form: 


$$
\begin{aligned}
F_{u g}=\kappa M_{a}^{2} P_{a} S_{a} & \left\{\left(1+\frac{1}{\kappa M_{a}^{2}}\right)\left[1-f_{1}^{a}(x)\right]+\right. \\
& \left.+\frac{\kappa(\kappa-1) M_{a}^{2}}{\kappa(\kappa-1) M_{a}^{2}-2} \sqrt{\frac{2}{\kappa+1}} \sqrt{\frac{\kappa-1}{2}+\frac{2}{M_{a}^{2}}+\frac{2}{(\kappa-1) M_{a}^{4}}}\left[1-f_{1}^{b}(x)\right]\right\}
\end{aligned}
$$

where:

$$
f_{1}(x)=\frac{1}{1+\left(\frac{r_{1}}{x}\right)^{2}}, \quad a=\frac{\kappa(\kappa-1) M_{a}^{2}}{2}+1 \quad \text { and } \quad b=\frac{\kappa(\kappa-1) M_{a}^{4}}{2}-1
$$

For launching a non-guided rockets from MLRS can be used gas-generator, which can provide higher initial velocity of rocket launch. In this way reduces the critical path which a maximum eccentricity of thrust performs rocket deflection from the line of fire. Previous experience provides successful experimental work with gasgenerator that can achieve initial velocity missiles from $110 \mathrm{~m} / \mathrm{s}$ and more.

Due to the gas generator launch may occur high recoil force in the direction of the line of fire that need balanced in order to obtain as much as possible recoilless weapon [3].

The total recoil force is obtained by sum of recoil force components profiles in the plane of shooting. These components are caused by gases flow through the gasgenerator exit and barrel inlet nozzles in both directions (Fig. 2).

$$
F_{\text {rtotal }}=F_{\text {rec } 1} \pm F_{r e c 2}-F_{\text {rec } 3}
$$

In order to meet the requirement of recoil dumping by forces balancing, base condition that the total recoil impulse during the action of all forces vs. time have to be zero. Corresponding delay in time design real impulses as the sum corresponds to zero, but front and back recoil appears, as the loading case.

Due to the emphasis of the propellant gas from gas-generator in the barrel the reactive force appears, acting on gas-generator connected on barrel:

$$
F_{r e c 1}=F_{g g 1}=h_{g g 1}^{\&} U_{e g g 1}+\left(p_{g g}-p_{c}\right) A_{m g g 1}
$$

The second component of the recoil force generated by the action of compressive forces in barrel on the frontal part of the gas-generator and bottom surface of barrel:

$$
F_{r e c 2}=F_{p c}-F_{g g 2}=p_{c} A_{g g}-\left[n{ }_{g g} U_{e g g 2}+\left(p_{g g}-p_{a}\right) A_{m g g 2}\right]
$$

The third component of the total recoil force caused by reactive effect of gas through the nozzle of barrel:

$$
F_{r e c 3}=F_{c}=n \&_{c} U_{e c}+\left(p_{c}-p_{a}\right) A_{m c}
$$




\section{COMPUTER SIMULATION OF LOADING MLRS DURING THE FIRING}

Based on these simplified mathematical models of gas-dynamic forces (2) which load MLRS during the firing and the adopted initial data for the $128 \mathrm{~mm}$ MLRS simulation was carried out in the MATLAB. In addition, the universal mathematical formulation is required, that could be, by easily model parameters modifying, wellapproximated the mentioned gas-dynamic forces $[3,4,5]$.

Fig. 3 shows simulation of total force shock loadings (simplified model) initiated by rockets exhaust jet over pressure, attack on front launcher plate at MLRS, during launching. Fig. 4 shows the simulated total internal ballistic force as recoil due to gas generator launching.

According to the semi-experimental theory, the impact forces of gases on the front panel of launcher and recoil forces for the gas generator launch, i.e., their changes vs. time, with an appropriate error, can be approximated by an exponential function of the form with variable coefficients $C$ and $a$ :

$$
F=C t e^{-a t}
$$

According to Ref. [1], coefficients $C$ and $a$, have order of $C \approx(1.5 \div 6.5) \cdot 10^{7}$ and $a \approx(500 \div 1000)$. Calculations show the best agreement in the simplified model with the parameters $C=2.3 \cdot 10^{7}, a=1000$ (Fig. 3, experimental exponential curve). These approximations from real proving ground measurements, needs estimations, of experimental or semi empirically exponential and linear coefficients, integrated in function of shock impulse force. That means no periodical behavior of initial forces, except during ripple fire, where shock impulses over-loop loadings in the manner of sinusoidal form vs. time. These would be usually inputs for design of all types of dumpers, able to constrain these shocks on the vehicle self-propelled platforms.

Since the law of exponential change (7) determined after measuring of the real force profile can be concluded that the simplified model well describes the establishment of maximum force profile, but not the profile of response after the maximum pressure stroke.

Load of MLRS circular support during firing is simulated based on scheme shown in Fig. 5. For the purposes of loads and stresses of MLRS determining, 3D simulation model of MLRS was developed in the ProENGINEER software package (Fig. 7) [3, 4].

Capability to transfer loadings into the mounted structure of equipment is essence of necessity for precise forces evaluation in the software simulation tests. Distribution on the bearing junction between, vehicle and launcher box with barrels estimated as critical surface exposed to the shock force on the vehicle. Examples shown in the Figs. 6 to 8 presented methodology provided in all cases of external forces and internal supports junctions and constrains. Full distribution result of the critical in simulations, around rigid circle bearing center, is given in the Fig. 9. 


\section{DUMPING SOLUTION AT MLRS ON VEHICLE TO LAUNCHER CONNECTION}

Absorber with no periodical dumping performances could be one of good solution in cases of MLRS designing and integration, because of expected no periodical behavior with in dumping process.

One of the best possible designs to absorb strong shocks with a periodic transient time functions, and possibility to integrate active control equipment for line of sight correction is wire rope absorber. New principle of design in wire rope absorber technology is given in $[6,7]$ with possible active computer control necessary for continual loop in line of sight correction during fire have numerous undetermined design challenges. Distributions of loading in all directions initiated design of ring form of absorber with possible active control of rings setting in horizontal plane (Fig. 10).

\section{EQUIPMENT FOR EXPERIMENTAL SIMULATIONS AND TESTING RESULTS}

Evaluation of absorber response behavior, on the impulse loading, and harmonic loading, is experimentally tested [7]. Output forces and displacements as expected responses on initiated shock forces are generated by test equipment. Absorber was shocked by impulse forces with extremely short time and, also, by continual oscillatory forces with different frequency and amplitude initiation performances form of approximation of impulses vs. time, measured by real behavior, and generated in the simulation tests on the equipment, is shown in the Fig. 11 [2, 7, 8].

Input ring of absorber, is measured from the tests with maximum forces approximated as the characteristic loading values presented in the Fig. 10, and as concentrated impulses of shocks. Testing equipment, which had ability to generate rapid forces and linear or nonlinear gradients vs. time (Fig. 11), is presented in the Fig. 12. Equipment was able to realize also harmonic oscillatory amplitudes of forces and displacements. Testing model [7] was wire rope absorber of ring form, Table 1.

Receiving of shock forces was on the input plate and was simulated from controlled pressing machine by test impulses generated with this equipment and by software. The fixed exit plate of absorber was connected with force transducer on the machine. Transducer tracked output force vs. time generated by input shock force, and distributed along absorber. Displacement of moveable plate was measured directly on press machine. When stick from the machine operates, attacking on the plate of absorber, as the input force generator in time, output data from experiments was output force measured on transducer and displacement of the machine stick. Wire rope ring absorber was designed as the model for specially weapon purposes. Absorber was able to use for experimental purposes more than hundred times without hysteresis deformations and displacements.

Processing equipment was divided in three canals: control canal for input commands and two measured canals for output data collection. Input data was taken from machine (displacement or force) and output data was taken from force transducer settled on the output plate of wire rope absorber. 
Table 1. Dimensions of experimental model.

\begin{tabular}{|c|c|}
\hline $\begin{array}{c}\text { Wire rope performances: } \\
\text { form } \\
\text { wire rope diameter } \\
\text { wire rope length } \\
\text { wire rope mass }\end{array}$ & $\begin{array}{c}6 \times 37 \\
10 \mathrm{~mm} \\
18 \mathrm{~m} \\
5.68 \mathrm{~kg}\end{array}$ \\
\hline Mass of absorber & $15 \mathrm{~kg}$ \\
\hline Ring diameter - out & $294 \mathrm{~mm}$ \\
\hline Inner diameter of ring & $280 \mathrm{~mm}$ \\
\hline Thickness of absorber & $72 \mathrm{~mm}$ \\
\hline Accelerometer position eccentricity & $120 \mathrm{~mm}$ \\
\hline
\end{tabular}

Set of equipment consists of:

1. Experimental hydraulic press machine "MTS - 810"

2. Inductive transducer of force integrated with hydraulic press machine

3. PC with AD/DA converter

4. Appropriate software

Connection between output plate and machine force transducer for dynamical output force measurement is jointed with total rigid steel stick [7]. Schedule of experiment is given in the Table 2.

Table 2. Schedule of experiment.

\begin{tabular}{|c|c|c|c|c|c|c|c|}
\hline \multicolumn{8}{|c|}{$\begin{array}{c}\text { Static overloading } \\
\mathrm{F}_{0=1500 \mathrm{~N}} \\
\text { Static initial } \\
\text { displacement } \mathrm{y}=10 \mathrm{~mm}\end{array}$} \\
\hline \multirow{2}{*}{$\begin{array}{l}\text { Exp. } \\
\text { No. }\end{array}$} & \multicolumn{3}{|c|}{$\begin{array}{c}\text { Linear form } \\
\text { of shock }\end{array}$} & \multirow{2}{*}{$\begin{array}{l}\text { Exp. } \\
\text { No. }\end{array}$} & \multicolumn{3}{|c|}{\begin{tabular}{|c|}
$\begin{array}{c}\text { Harmonic } \\
\text { forms }\end{array}$ \\
\end{tabular}} \\
\hline & $F_{m}$ & $t_{m}$ & $t_{k}$ & & $F_{\mathbf{m}}$ & $\mathbf{f}$ & $\mathbf{n}$ \\
\hline & $\mathrm{kN}$ & $\mathrm{ms}$ & $\mathrm{ms}$ & & $\mathrm{kN}$ & $\mathrm{Hz}$ & - \\
\hline 1 & 1 & 1 & 10 & 9 & 0.6 & 2 & 10 \\
\hline 2 & 1.5 & 1 & 10 & 10 & 0.6 & 5 & 10 \\
\hline 3 & 1.75 & 1 & 10 & 11 & 0.6 & 20 & 100 \\
\hline 4 & 2 & 1 & 10 & 12 & 1.5 & 10 & 100 \\
\hline 5 & 3 & 1 & 10 & & & & \\
\hline 6 & 4 & 1 & 10 & & & & \\
\hline 7 & 5 & 1 & 10 & & & & \\
\hline 8 & 6 & 1 & 10 & & & & \\
\hline
\end{tabular}

Processing equipment was divided in three canals: control canal for input commands and two measured canals for output data collection. Input data was taken from machine (displacement or force) and output data was taken from force transducer settled on the output plate of wire rope absorber. 
Experimental results are represented on diagrams (Fig. 12,13,14 and 15). In Fig. 12 is represented measured displacements response on to the initial linear shocks in time.

The graphics in the Fig. 13 represents output forces vs. time for the harmonic forces initiation Three-dimensional graphs, Fig. 14 and 15, have appropriate moment of time where the maximum of output (internal) force and displacement have realized. These figures show existence of time delaying between maximum amplitudes.

\section{CONCLUSIONS}

- According to reference [9], characteristics generally fall into two load ranges: small amplitude and relatively large amplitude displacement. Damping is a combination of frictional interaction of sliding wire strands within the cable loop (coulomb damping) and viscous effects dependent on the relative velocity across the mount. Transmissibility, as ratio between outputs dumped forces and input shock forces, for their maximum values, shows approximately linear function, at small displacement is characterized as 3$3.5: 1$. This shows good dumping of force magnitudes in absorber. According to experiments $[7,8]$, approximated expression of forces is:

$$
F_{\text {inp }}^{\max }=3.5 F_{\text {out }}^{\max }
$$

Expression shows behavior which means small inclinations of constant dumping properties measured by amplitude in the given interval of measurement.

- Projection of red curve in the Fig. 16 shows squared root ratio between maximum forces and related maximum displacements derived by experimental equation in the form:

$$
F_{\text {inp }}^{\max }=\sqrt{3 y_{\max }}
$$

All that, directed on the conclusions that hysteretic behavior guided process of loading and reloading during shocks. Data given in [9] shows identical forms of behavior. This orientated on the hysteretic behavior caused by lateral and axial stiffness corresponding to linear non-ring form absorber [9].

- Obviously, stiffness is not constant function for the short impulse loading.

- Achieving time of displacements changes, depend of input impulse intensity (Fig. 13). This time interval vary vs. loading intensity, but keeps constant ratio between increasing and decreasing loading gradients in the given time interval (Fig. 15).

- Frequency behavior does not have any input and output modulation, which is typical for linear behavior with large dumping of mechanical absorbers. 
- Approximated exponential function of input shock loadings is well base for typical military forces appeared on the weapon in different circumstances. Corresponding impulse treatment remains basic dynamic property for evaluations of weapon performances. Absorbing of shocks on the mechanical parts of weapon platforms is provided by new type of wire rope absorber with dumping nonlinearities, which guided absorbing process.

\section{ACKNOWLEDGEMENT}

This work is a contribution to the Ministry of Science and Technological Development of Serbia funded projects III 47029 in 2011 year.

\section{REFERENCES}

[1] Milinovic M., Basics of launcher and rocket design (in Serbian), Faculty of mechanical engineering, Belgrade, (2002).

[2] Mosakovski V. and Makarenkov A., The strength of rocket constructions (in Russian), High school, Moscow, (1990).

[3] Kari A., Performance improvement of launching and firing with MLRS using special mechanisms of relying, Master thesis, Faculty of mechanical engineering, University of Belgrade, (2007).

[4] Toogood R., Pro Mechanica Structure Tutorial, Mechanical Engineering, University of Alberta, SDC Publications, Canada, (2002).

[5] Milinović $M$, Jeremić $O$, "Approximate criteria of impulse shock for combat loading dumping", OTEH, Belgrade, Serbia, (2005).

[6] Patent No. RS 1076U, Intellectual Property Office of the Republic of Serbia, 2009

[7] Kari A., Milinovic M. and Jeremic O. "Experimental model of wire rope absorber", KOD, Conference Proceedings p. 335-338., (2008).

[8] Milinovic M., Jeremic O. and Kari A., "Time behavior of nonlinear absorber attacking by shock impulse forces", $2^{\text {nd }}$ IConSSM 2009, Palic, Serbia, (2009).

[9] Piersol, A. G. and Paez, T. L., Harris' shock and vibration handbook, Sixth Edition, The McGraw-Hill Companies, Inc, New York, USA, (2010). 


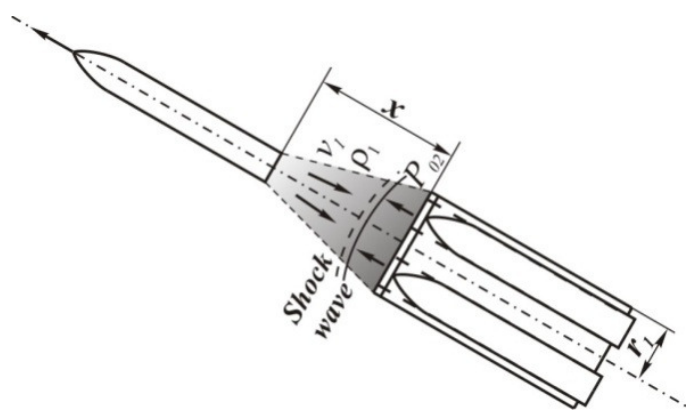

Fig. 1. Fire shock loading.

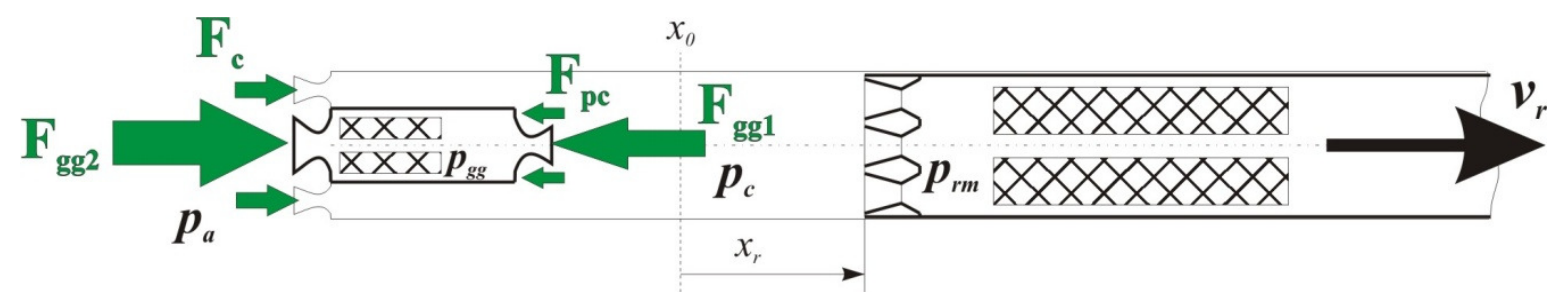

Fig. 2. Shock loadings during gas-generator launching.

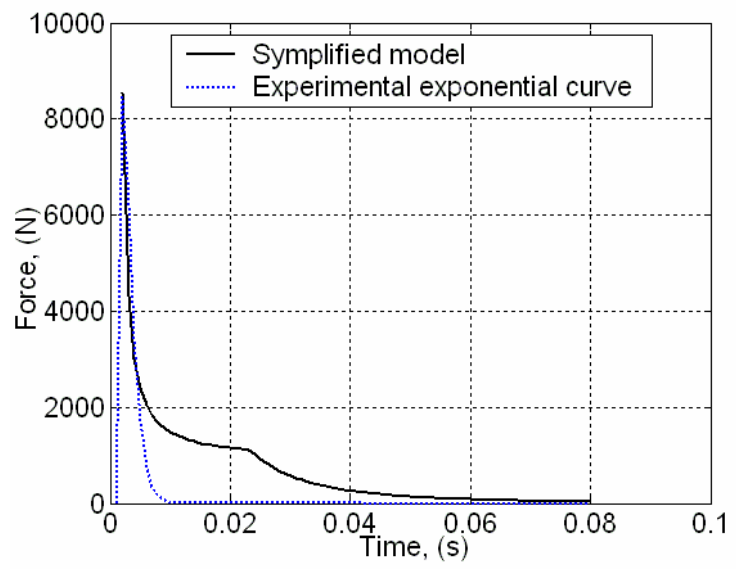

Fig. 3. Shock loadings initiated by rockets exhaust jet over pressure.

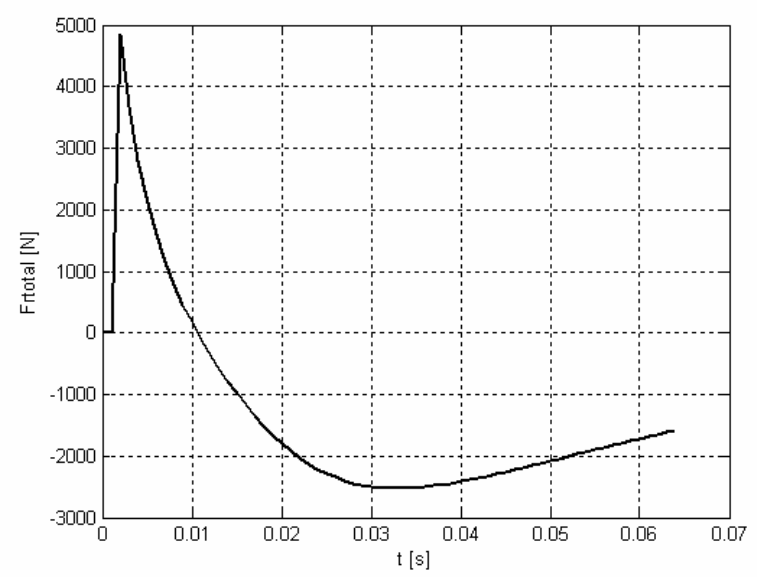

Fig. 4. Total force recoil due to gas generator launching. 


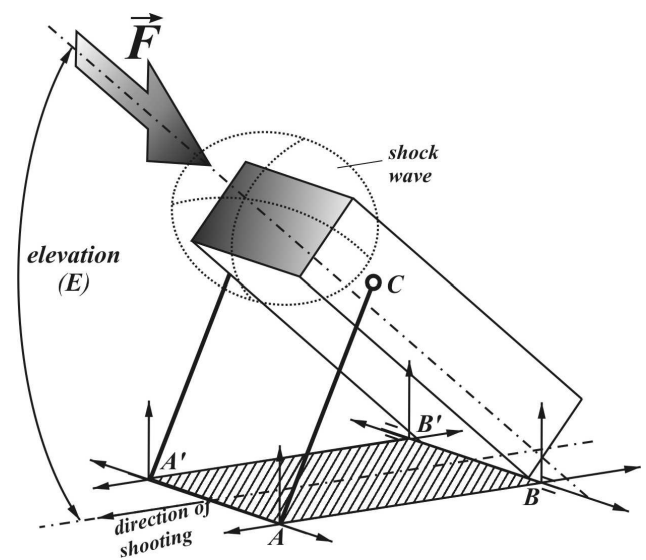

Fig. 5. Scheme of MLRS loading during firing.

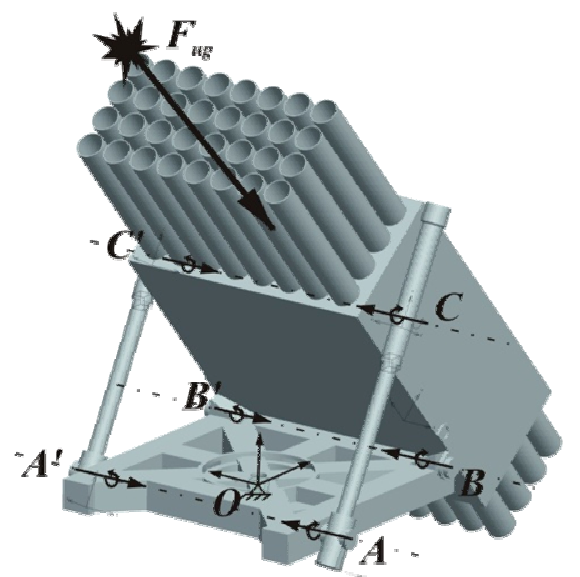

Fig. 6. Simulation 3D model in ProEngineer.

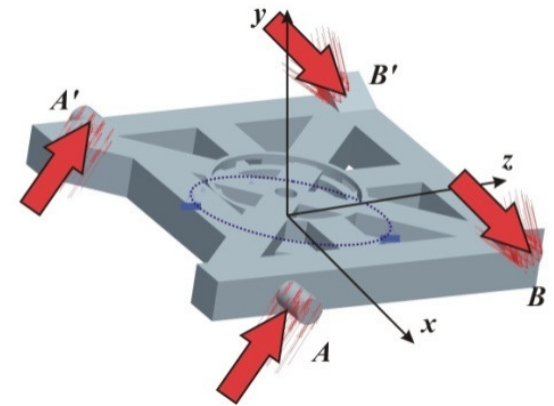

Fig. 7. Load of the launcher cradle.

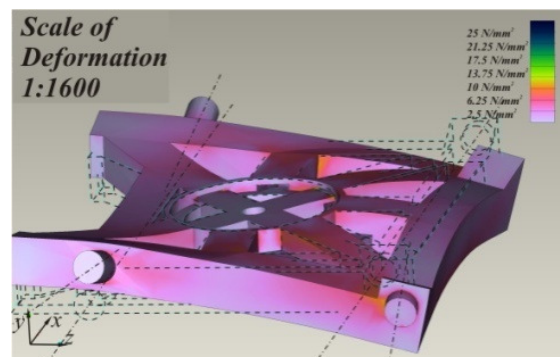

Fig. 8. Simulation of cradle deformations. 


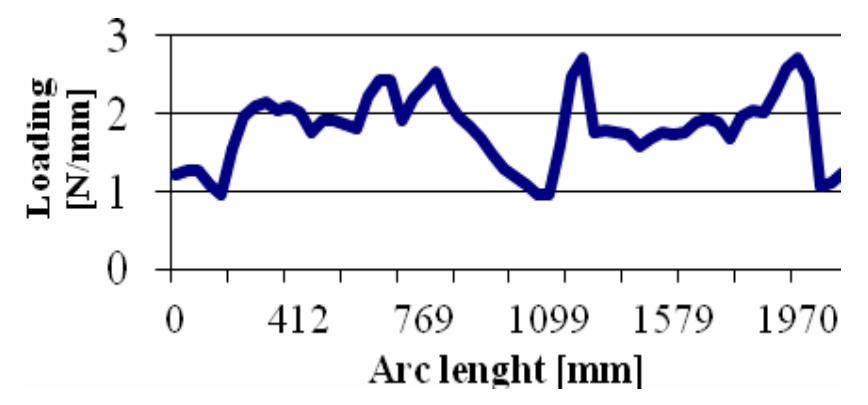

Fig. 9. Circular line distribution loading of shock force.

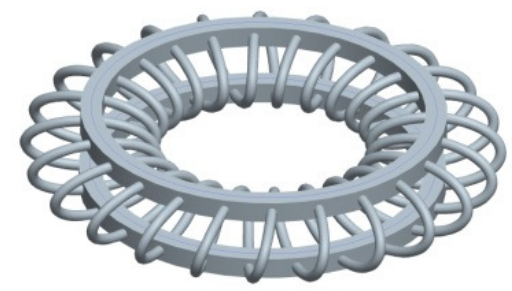

Fig. 10. Ring wire rope absorber.

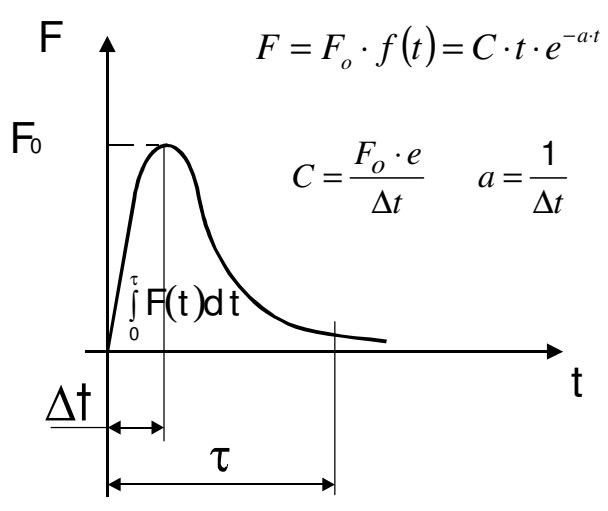

a) Real forces behavior

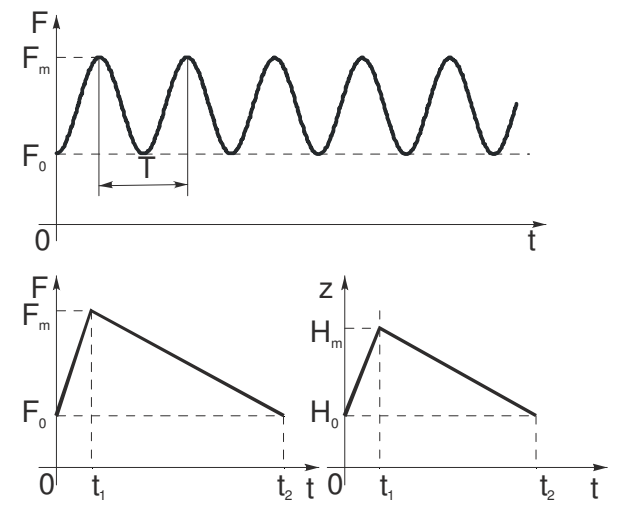

b) Approximated impulse on the test equipment

Fig. 11. Approximations from real proving ground measurements to the Laboratory simulations of forces and displacements.

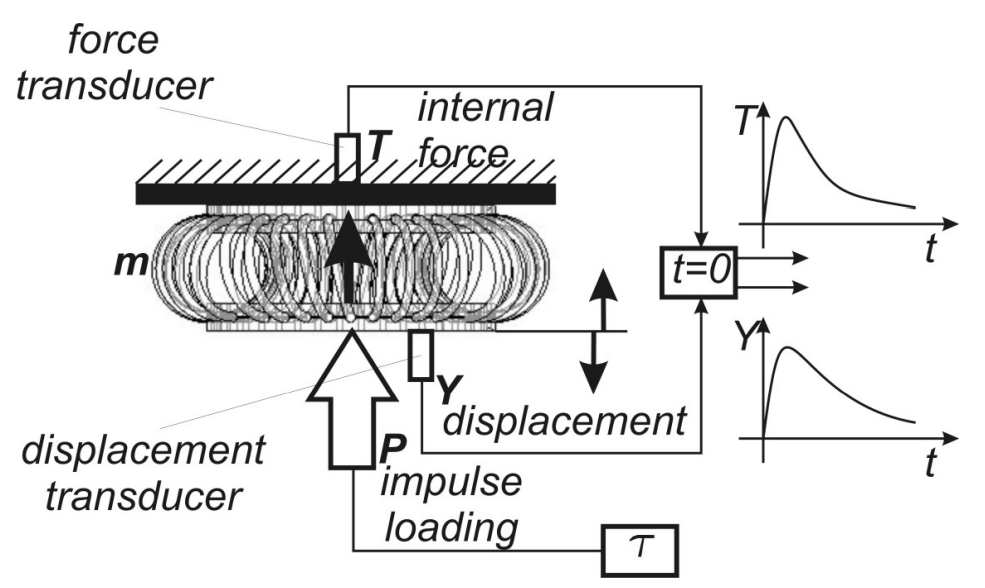

Fig. 12. Measurement and equipment with experimental and control data links. 


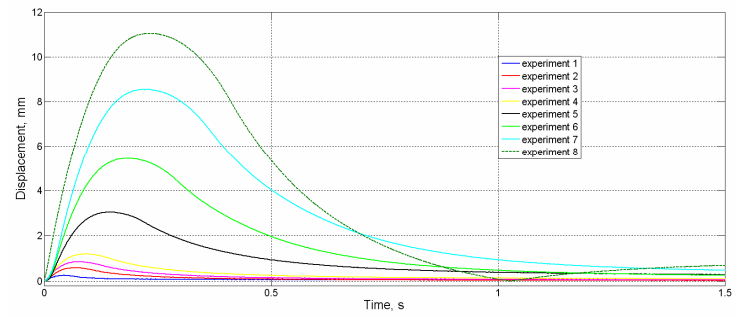

Fig. 13. Output displacement of movable plate

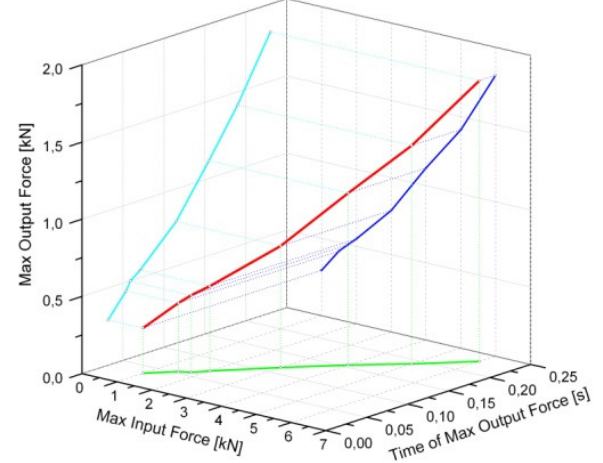

Fig. 15. Three-dimensional graph max. output force - input force - time

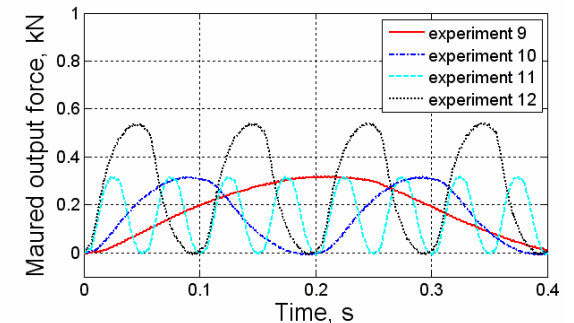

Fig. 14. Output force initiated by harmonic oscillatory input force

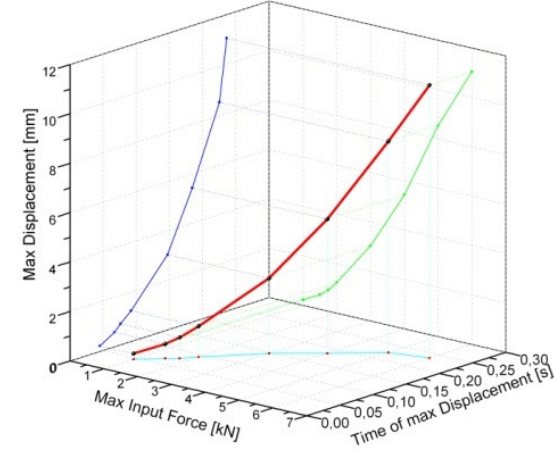

Fig. 16. Three-dimensional graph max. displacement- input force - time 